\title{
SARS-CoV-2 specific cellular response following COVID-19 vaccination in patients with chronic lymphocytic leukemia
}

\author{
Sibylle C. Mellinghoff $\mathbb{I D}^{1,2,3 凶}$, Sandra Robrecht ${ }^{1}$, Leonie Mayer $\mathbb{( D}^{3,4,5}$, Leonie M. Weskamm (iD ${ }^{3,4,5}$, Christine Dahlke (D) ${ }^{3,4,5}$, \\ Henning Gruell $\mathbb{D}^{6}{ }^{6}$, Kanika Vanshylla ${ }^{6}$, Hans A. Schlösser ${ }^{7}$, Martin Thelen $\mathbb{D}^{7}$, Anna-Maria Fink (D) ${ }^{1}$, Kirsten Fischer ${ }^{1}$, Florian Klein $^{6}$, \\ Marylyn M. Addo (iD ${ }^{3,4,5}$, Barbara Eichhorst ${ }^{1}$, Michael Hallek ${ }^{1}$ and Petra Langerbeins (D) ${ }^{1}$
}

(c) The Author(s) 2021

Leukemia (2022) 36:562-565; https://doi.org/10.1038/s41375-021-01500-1

Chatzikonstantinou et al. [1] conducted a large follow-up analysis of COVID-19 in patients with chronic lymphocytic leukemia (CLL) and confirmed a high mortality rate, especially in patients with older age, comorbidity and previous CLL-treatment. The results emphasize the importance of prevention and mitigation of COVID-19 by vaccination, especially in patients with hematological malignancies. The COVID-19 vaccine-induced immunity is mediated by the interaction of both, humoral and cellular components $[2,3]$. While several studies have confirmed low humoral immunogenicity in CLL patients [4-7], very few describe cellular responses to determine immunogenicity and report reduced $\mathrm{T}$ cell response [8]. In this prospective cohort study, we hence investigated cellular immunogenicity and the interplay with humoral immunogenicity following COVID-19 vaccination in SLL/CLL patients as compared with healthy controls $(\mathrm{HC}$ ).

Blood samples of CLL registry (NCT02863692) patients were centrally evaluated after full COVID-19 vaccination. In total, 21/23 patients were included in the analyses (samples missing in $2 / 23$ ). Vaccinated healthcare workers served as HC cohort $(n=12)$. Both studies were approved by the local ethics committee.

Patient and disease characteristics and vaccination schedules are summarized in Table 1 and Supplemental Table 1. Patient blood samples were collected at a median of 47 (range 19-94 days) and $\mathrm{HC}$ at a median of 35 (range 32-38) days after the second vaccination

SARS-CoV-2 receptor-binding domain (RBD) specific lgG antibodies, determined using Alinity ci SARS-CoV-2 lgG II Quant assay (Abbott), were detectable in $8 / 21$ (38.1\%) patients with SLL/CLL and $100 \%$ of $\mathrm{HC}(p=0.001$; Fig. $1 \mathrm{~A}, \mathrm{~B})$. Neutralizing activity, determined by using heat-inactivated serum in a lentiviral-based pseudovirus neutralization assay against Wu-01 strain of SARS-CoV-2, was observed in serum samples from all HC (GeoMean ID ${ }_{50}$ 409) (Fig. 1C). No neutralizing activity $\left(\mathrm{ID}_{50}<10\right)$ was detectable in the majority of CLL patients $(14 / 21,67 \%, 0)$, including all seronegative individuals.
However, CLL patients with detectable activity $(7 / 21,30 \%)$ had a response that was comparable to $\mathrm{HC}\left(\mathrm{ID}_{50} 523, p=0.9\right)$.

Peripheral blood mononuclear cells (PBMCs) were used for SARSCoV-2 spike-specific T cells (Human IFNy ELISpot ${ }^{\text {PLUS }}$ [ALP] kit [Mabtech]) and B cells (IgG ELISpot) analyses. Results are reported as spot-forming cells (SFC) per million PBMCs. T cell responses to SARSCoV-2 peptide pool ([15-mers overlapping by 11 amino acids] spanning the entire spike protein) were considered positive if higher than twice the median response of pre-pandemic HC (48 SFC/106). The median number of SARS-CoV-2 specific T cells was 21.3. SFC (interquartile range [IQR] 0.0-145.0) for CLL patients as compared with 177.3 SFC [IQR 138.0-403.3] in HC ( $p=0.008$; Fig. 1D). While 8/ 21 (38.1\%) CLL patients had a SARS-CoV-2 spike-specific T cell response measurable above cut-off, $90 \%$ of $\mathrm{HC}$ mounted a response $(p=0.009)$

SARS-CoV-2 S1/2-specific antibody-secreting cells (ASC) were analyzed in 14/21 (66.7\%) SLL/CLL patients. The cut-off value for positive responses were defined as the mean plus two standard deviations of the responses observed in pre-pandemic HC (62 SFC/ $\left.10^{6}\right)$. Overall, $1 / 14 \mathrm{SLL} / \mathrm{CLL}$ patients $(7.1 \%)$ had detectable S-specific ASC (138 SFC) as compared with $100 \%$ in HC (median 193 SFC, range 89-464 SFC). The SARS-CoV-2 specific IgG titer of the ASC responding patient was with $11360 \mathrm{BAU} / \mathrm{ml}$ the highest within the group of CLL patients. Looking at total IgG-secreting $B$ cells, 13 patients without S-specific ASC did neither show any lgG-secreting B cells. Spots were too faint to be counted or detected at numbers below the cut-off.

In a descriptive analysis (Table 1 and Supplemental Table 2 and $3)$, potential variables to be associated with humoral and $T$ cell responses were investigated. While 3/21 (14.3\%) of patients had both a humoral and a T cellular response, eight patients (38.1\%) were double negative and a discordant response, defined by detection of either $\mathrm{T}$ cellular or humoral immune response to vaccination was found in most patients $(10 / 21,47.6 \%)$.

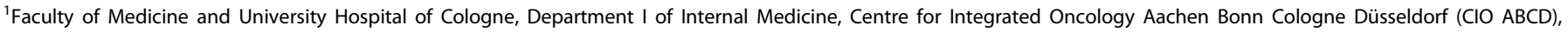

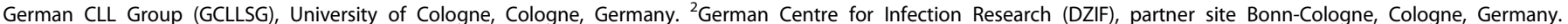

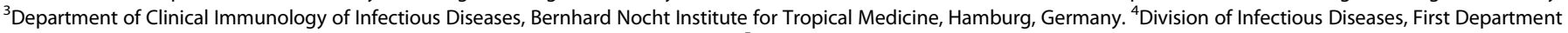

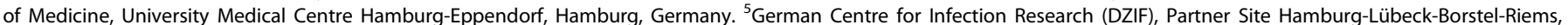

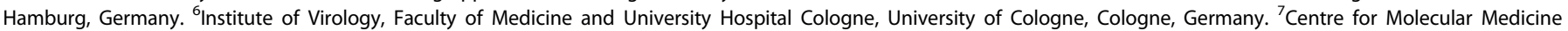
Cologne, University of Cologne, Faculty of Medicine and University Hospital Cologne, Cologne, Germany. ${ }^{凶}$ email: sibylle.mellinghoff@uk-koeln.de
}

Received: 8 November 2021 Revised: 2 December 2021 Accepted: 10 December 2021

Published online: 22 December 2021 
Table 1. Patients baseline characteristics and disease characteristics in the overall cohort and by subgroups.

\begin{tabular}{|c|c|c|c|c|c|}
\hline \multirow[t]{2}{*}{ Parameters N (\%) } & \multicolumn{5}{|c|}{ Patients with CLL ( $N=23$ ) } \\
\hline & Overall cohort & $\begin{array}{l}\text { Humoral response } \\
\text { negative T cell } \\
\text { response negative }\end{array}$ & $\begin{array}{l}\text { Humoral response } \\
\text { negative, } \mathrm{T} \text { cell } \\
\text { response positive }\end{array}$ & $\begin{array}{l}\text { Humoral response } \\
\text { positive, } \mathrm{T} \text { cell } \\
\text { response negative }\end{array}$ & $\begin{array}{l}\text { Humoral response } \\
\text { positive, } \mathrm{T} \text { cell } \\
\text { response positive }\end{array}$ \\
\hline $\begin{array}{l}\text { Age, median (range) } \\
\text { (years) }\end{array}$ & $70(46-79)$ & $70.5(48-79)$ & $71.0(53-79)$ & $74.0(62-77)$ & $59.0(49-62)$ \\
\hline$>65$ & $13(56.5)$ & $6(75.0)$ & $3(60.0)$ & $4(80.0)$ & $0(0.0)$ \\
\hline$>70$ & $11(47.8)$ & $4(50.0)$ & $3(60.0)$ & $4(80.0)$ & $0(0.0)$ \\
\hline Male sex & $20(87)$ & $6(75.0)$ & $4(80.0)$ & $5(100.0)$ & $3(100.0)$ \\
\hline \multicolumn{6}{|l|}{ Disease / treatment status } \\
\hline Treatment-naïve & $1(4.3)$ & $0(0.0)$ & $0(0.0)$ & $1(20.0)$ & $0(0.0)$ \\
\hline $1^{\text {st }}$ line & $6(27.3)$ & $2(25.0)$ & $0(0.0)$ & $2(50.0)$ & $1(33.3)$ \\
\hline$>1^{\text {st }}$ line & $16(72.7)$ & $6(75.0)$ & $5(100.0)$ & $2(40.0)$ & $2(66.7)$ \\
\hline $\begin{array}{l}\text { Treatment }<12 \text { months } \\
\text { prior vaccination }\end{array}$ & $9(40.9)$ & $3(37.5)$ & $4(80.0)$ & $1(25.0)$ & $0(0.0)$ \\
\hline without anti $\mathrm{CD} 20^{\mathrm{b}}$ & $2(9.1)$ & $0(0.0)$ & $1(20.0)$ & $1(20.0)$ & $0(0.0)$ \\
\hline with anti $C D 20^{c}$ & $7(31.8)$ & $3(37.5)$ & $3(60.0)$ & $0(0.0)$ & $0(0.0)$ \\
\hline $\begin{array}{l}\text { Type according to } \\
\text { hierarchical model }^{\mathrm{d}}\end{array}$ & $21(91.3)$ & & & & \\
\hline $\operatorname{del}(17 p)$ & $4(19.0)$ & $3(37.5)$ & $1(20.0)$ & $0(0.0)$ & $0(0.0)$ \\
\hline TP53 mutational status & $19(82.6)$ & & & & \\
\hline Mutated & $2(10.5)$ & $5(71.4)$ & $4(100.0)$ & $3(100.0)$ & $3(100.0)$ \\
\hline Unmutated & $17(89.5)$ & $2(28.6)$ & $0(0.0)$ & $0(0.0)$ & $0(0.0)$ \\
\hline
\end{tabular}

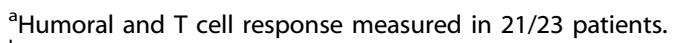

${ }^{\mathrm{b}}$ Acalabrutinib, Ibrutinib.

'Obinutuzumab, Obinutuzumab/Venetoclax, Acalabrutinib/Obinutuzumab, Acalabrutinib/Obinutuzumab/Venetoclax.

${ }^{\mathrm{d} C y t o g e n e t i c ~ s u b g r o u p s ~ w e r e ~ d e t e r m i n e d ~ a c c o r d i n g ~ t o ~ t h e ~ h i e r a r c h i c a l ~ m o d e l ~ o f ~ D o ̈ h n e r ~ e t ~ a l . ~[11] . ~}$

In conclusion, humoral and cellular immunogenicity following COVID-19 vaccination was significantly impaired in patients with SLL/CLL as described previously. SARS-CoV-2 specific antibodies and $\mathrm{T}$ cells were detectable in $38.1 \%$ each. In the majority of seroconverted patients, SARS-CoV-2 neutralizing serum activity of diverse magnitude was detectable indicating functionality of antibodies if at all mounted. While less than $15 \%$ of patients had both a humoral and cellular response, most patients showed a discordant response with only either detectable humoral or cellular response. Clinical features of the two subgroups differed with regard to previous treatment lines, which seem to affect the humoral more than the T cell axis. CLL-targeted treatments as well the underlying diseases itself affect $B$ cells and self-evidently impact the humoral response. Our findings encourage immunization of patients even at advanced disease stages or heavily pre-treated as a subgroup that may respond with the $\mathrm{T}$ cellular axis.

Two patients showed a particular strong $T$ cell response: One had been vaccinated thrice and the other had received a heterologous boosting (Fig. 1D). Data from more patients will need to prove if a booster vaccination is more likely to induce $T$ cell response. Our data emphasize the importance of assessing the $T$ cell response in patients with a limited serologic response. The best vaccination regime to promote those key players remains to be investigated. While heterologous immunization appears to elicit stronger $T$ cell responses than homologous immunization [9], the chronological order for immunocompromised patients is unclear and needs further study.

A limitation of this study is the small sample size and the younger age of the control group (as compared with the SLL/CLL 
A

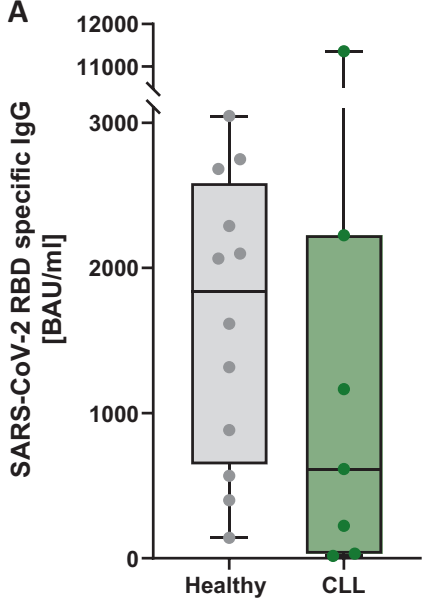

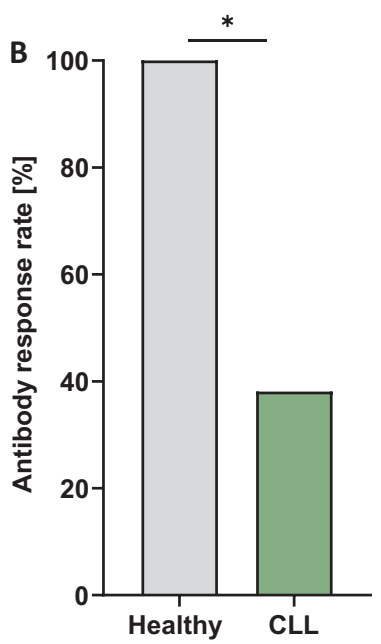

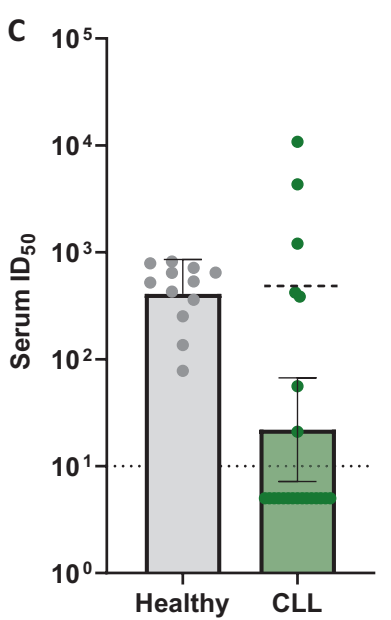

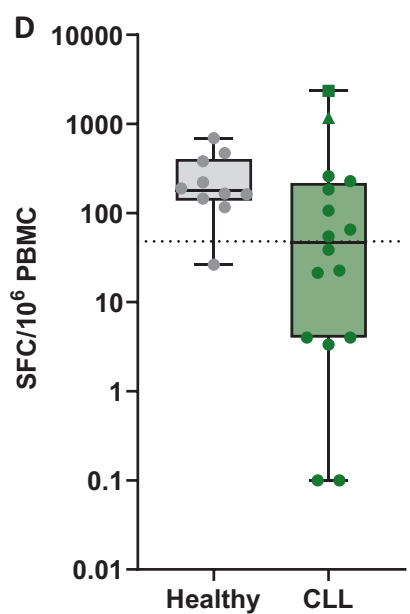

Fig. 1 Humoral and T cell immune responses after COVID-19 vaccination. A SARS-CoV-2 RBD specific lgG in CLL patients (median 889.9 BAU/ $\mathrm{ml}$, IQR 80.2-2127.4, for responders) and healthy controls (median 1839.8 BAU/ml, IQR 647.0-2583.4) measured by ELISA. B Antibody response rate in CLL patients and healthy volunteers. ${ }^{*} p=0.001$. C Serum neutralizing activity ( $50 \%$ inhibitory serum dilution) determined in a pseudovirus neutralizing assay against the Wu-01 pseudovirus strain. Bars indicating geometric mean ID50 with $95 \%$ confidence intervals. A dashed line indicates limit of detection [10]. Samples with no detectable neutralization $\left(\mathrm{ID}_{50}<10\right)$ were plotted with an arbitrary $I \mathrm{D}_{50}$ of 5 for graphical representation. Dashed line in the CLL group shows geometric mean ID50 for individuals with a detectable neutralizing response. D Interferon-y T cell ELISpot response in CLL patients and HC. Shown values are mean spots in peptide-stimulated wells minus background in negative control wells. Error bars represent median \pm interquartile range. The dotted line indicates the positive threshold of 48 SFC/10 ${ }^{6}$ PBMC. Samples were acquired 35 days after the second vaccination in $\mathrm{HC}$ and at a median of 47 days after second vaccination in CLL patients. Two patients had much higher correlated of T cell immunity after vaccination: One was vaccinated thrice and one was the only patient of the entire cohort that had received heterologous prime-boost immunization with BNT162b and ChAdOx1. BNT BNT162b, ChAd ChAdOx1, HC Healthy Control.

patients), as older individuals respond with lower antibody levels to vaccination. However, in the rather small fraction of SLL/CLL patients who responded to vaccination, similar titers of neutralizing antibodies were detectable in HC. Further, we only included one treatment-naïve patient and therefore cannot fully conclude the impact of CLL-directed treatment as compared with untreated CLL on cellular immunity. Previous trials reported inferior serologic immunogenicity in treatment-naïve patients as compared with patients previously treated $[4,5,10]$. Future studies should provide more data comparing those two subgroups of CLL patients and further focus on cellular immunity.

In conclusion, we demonstrate inferior T cell response to COVID-19 vaccines in SLL/CLL patients as compared with HC, supporting the importance of a third vaccine dose for those. The prime-boost regime, in particular the choice of best vaccine combination, is yet to determine. Our observation of discordant immune responses in the majority of patients indicates that the humoral response may not be reliable as the sole surrogate marker of protection in the patients with CLL and further B cell depleting malignancies, at least if negative.

\section{REFERENCES}

1. Chatzikonstantinou T, Kapetanakis A, Scarfò L, Karakatsoulis G, Allsup D, Cabrero AA, et al. COVID-19 severity and mortality in patients with CLL: An update of the international ERIC and Campus CLL study. Leukemia. 2021;35:3444-54.

2. Koch T, Mellinghoff SC, Shamsrizi P, Addo MM, Dahlke C. Correlates of vaccineinduced protection against SARS-CoV-2. Vaccines. 2021;9:238.

3. Braun J, Loyal L, Frentsch M, Wendisch D, Georg P, Kurth F, et al. SARS-CoV-2-reactive T cells in healthy donors and patients with COVID-19. Nature. 2020;587:270-4.

4. Benjamini O, Rokach L, Itchaki G, Braester A, Shvidel L, Goldschmidt N, et al. Safety and efficacy of BNT162b mRNA Covid19 Vaccine in patients with chronic lymphocytic leukemia. Haematologica. 2021. https://doi.org/10.3324/haematol.2021.279196. Epub ahead of print.

5. Herishanu Y, Avivi I, Aharon A, Shefer G, Levi S, Bronstein Y, et al. Efficacy of the BNT162b2 mRNA COVID-19 vaccine in patients with chronic lymphocytic leukemia. Blood. 2021;137:3165-73.

6. Tadmor T, Benjamini O, Braester A, Rahav G, Rokach L. Antibody persistence 100 days following the second dose of BNT162b mRNA Covid19 vaccine in patients with chronic lymphocytic leukemia. Leukemia. 2021;35:2727-30.
7. Parry H, Mcllroy G, Bruton R, Ali M, Stephens C, Damery S, et al. Antibody responses after first and second Covid-19 vaccination in patients with chronic lymphocytic leukaemia. Blood. Cancer J. 2021;11:136.

8. Ehmsen S, Asmussen A, Jeppesen SS, Nilsson AC, Østerlev S, Vestergaard $H$, et al. Antibody and T cell immune responses following mRNA COVID-19 vaccination in patients with cancer. Cancer Cell. 2021;39:1034-6.

9. Pozzetto B, Legros V, Djebali S, Barateau V, Guibert N, Villard M, et al. Immunogenicity and efficacy of heterologous ChAdOx1-BNT162b2 vaccination. Nature. 2021. https://doi.org/10.1038/s41586-021-04120-y. Epub ahead of print.

10. da Cunha-Bang C, Kirkby NS, Friis-Hansen L, Niemann CU. Serological response following vaccination with BNT162b2 mRNA in patients with chronic lymphocytic leukemia. Leuk Lymphoma. 2021:1-3. https://doi.org/10.1080/10428194.2021.1973673. Epub ahead of print.

11. Döhner $H$, Stilgenbauer $S$, Benner A, Leupolt $E$, Kröber A, Bullinger $L$, et al. Genomic aberrations and survival in chronic lymphocytic leukemia. N Engl J Med. 2000;343:1910-6.

\section{ACKNOWLEDGEMENTS}

We thank the working groups of PD Hans-Anton Schlößer, Florian Klein, and Marylyn M. Addo for all logistical and technical support. Especially, we thank Larisa Idrizovic and Tatjana Lammertz for their continuous support.

\section{AUTHOR CONTRIBUTIONS}

SCM and PL implemented the research and design of the study. They were responsible for data assessment, coordination, and conduction of the study and authored the paper. SR performed the statistical analyses and co-authored the paper. LMW and LM performed the T and B cell vaccine response laboratory analyses and co-authored the paper. HG and KV the humoral vaccine response laboratory analyses and co-authored the manuscript. HAS and MT performed blood sample processing and co-authored the paper. $\mathrm{CD}, \mathrm{MMA}, \mathrm{FK}, \mathrm{AMF}, \mathrm{KF}, \mathrm{BE}$, and $\mathrm{MH}$ supervised the conduct of the study, gave advice for study design and laboratory analyses, and coauthored the paper.

\section{FUNDING}

Open Access funding enabled and organized by Projekt DEAL. 


\section{COMPETING INTERESTS}

SCM reports grants from DZIF (Clinical Leave Stipend). AMF reports research funding from Celgene/Bristol Myers Squibb (Inst), AstraZeneca (Inst), and travel Expenses by AbbVie. KF reports other from Roche, other from AbbVie. BE reports grants and personal fees from Janssen-Cilag, grants and personal fees from Roche, personal fees from Novartis, grants and personal fees from AbbVie, personal fees from Celgene, personal fees from ArQule, personal fees from AstraZeneca, personal fees from Oxford Biomedica (UK), grants and personal fees from Gilead, grants from BeiGene, outside the submitted work. MH reports other from AbbVie, other from F. HoffmanLaRoche, other from Gilead, other from Janssen-Cilag, other from Mundipharma, during the conduct of the study. PL reports grants and personal fees from JanssenCilag, personal fees from Abbvie, other from F. Hoffman-LaRoche, personal fees from AstraZeneca. The remaining authors declare no competing financial interests for this study.

\section{ADDITIONAL INFORMATION}

Supplementary information The online version contains supplementary material available at https://doi.org/10.1038/s41375-021-01500-1.

Correspondence and requests for materials should be addressed to Sibylle $C$. Mellinghoff.
Reprints and permission information is available at http://www.nature.com/ reprints

Publisher's note Springer Nature remains neutral with regard to jurisdictional claims in published maps and institutional affiliations.

By Attribution 4.0 International License, which permits use, sharing, adaptation, distribution and reproduction in any medium or format, as long as you give appropriate credit to the original author(s) and the source, provide a link to the Creative Commons license, and indicate if changes were made. The images or other third party material in this article are included in the article's Creative Commons license, unless indicated otherwise in a credit line to the material. If material is not included in the article's Creative Commons license and your intended use is not permitted by statutory regulation or exceeds the permitted use, you will need to obtain permission directly from the copyright holder. To view a copy of this license, visit http://creativecommons. org/licenses/by/4.0/.

(c) The Author(s) 2021 